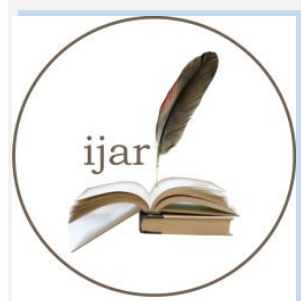

ISSN NO. 2320-5407
Journal Homepage: - www.journalijar.com INTERNATIONAL JOURNAL OF ADVANCED RESEARCH (IJAR)

Article DOI: $10.21474 /$ IJAR01/1519

DOI URL: http://dx.doi.org/10.21474/IJAR01/1519
INTERNATIONAL JOURNAL OF ADVANCED RESEARCH (JJAR)

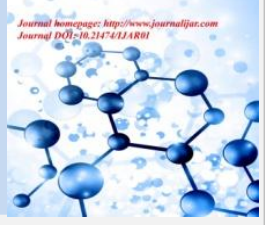

RESEARCH ARTICLE

\title{
IS BREAST ARTERIAL CALCIFICATION A RELIABLE INDICATOR OF CORONARY ARTERY DISEASE?
}

Fatma, Mohamed and Awad

\section{Manuscript Info}

Manuscript History

Received: 13 July 2016

Final Accepted: 12 August 2016

Published: September 2016

Key words:-

Breast arterial calcification, calcium scoring, coronary CT Angiography.

\section{Abstract}

Background:- The objective of this study is to detect if the presence of breast artery calcification (BAC) on mammograms is associated with an increased risk of coronary artery disease.

Materials and Methods:- This is a retrospective study performed in the period from January, 2011 until January, 2015. Females included in the study were those who had Computed Tomography Coronary Angiography (CTCA) done within one year of mammography, which showed breast arterial calcification (BAC).Breast artery calcification (BAC) was classified into mild, moderate, or severe. The presence of coronary artery calcification(CAC) and the calcium score were determined for all females. With respect to coronary artery stenosis, patients were classified into three groups: normal (no stenosis), nonsignificant stenosis (less than 50\% of luminal narrowing), or significant stenosis (equal to or more than $50 \%$ of luminal narrowing) (15). The correlation between BAC site and severity, CAC scoresand coronary artery stenosis was determined.

Results:- Forty-four females had breast arterial calcification (BAC), and Computed Tomography Coronary Angiography (CTCA) done within one year of mammography. The mean age of those females was $63.41 \pm 8.12$ years. $15 \%$ of the females with BAC and coronary artery calcification had unilateral BAC, while $85 \%$ of them had bilateral BAC, the correlation of which was statistically significant. There was also a significant difference between females with BAC and coronary artery calcification (59\%) and those with BAC and no coronary artery calcification $(41 \%)$. On the other hand, females with severe BAC and non-significant coronary artery stenosis were less than those with moderate BAC and coronary artery stenosis $(25 \%$ and $37.5 \%$, respectively). In addition, there was no significant correlation between the severity of BAC and CAC scores $(r: 0.08, P:<0.05)$.

Conclusion:- The presence of BAC is associated with a high incidence of coronary artery calcification. However, the severity of BAC has no significant correlation with CAC scores or coronary artery disease on CTCA. 


\section{Introduction:-}

Acute myocardial infarction is the leading cause of death among women over the age of 40 years $(1,2)$. Calcium deposition in the vascular wall is a common feature of degenerative atherosclerotic disease $(3,4,5,6)$. Computed tomography coronary angiography (CTCA) is a non-invasive imaging method used to estimate coronary artery calcification, with coronary artery calcium (CAC) score being the indicator of subclinical atherosclerosis and risk of coronary artery disease (7).

The prevalence of breast arterial calcifications (BAC) ranges from $9 \%$ to $17 \%$ for the female population and exceeds $50 \%$ among females aged 65 years and above (8). Several investigations have suggested BAC as a marker of arterial disease that could be associated with increased risk of cardiac events $(9,10)$. On the other hand, other studies have reported no significant association between BAC and cardiovascular diseases $(11,12,13)$.

The objective of this study is to detect if the presence of breast artery calcification (BAC) on mammograms is associated with an increased risk of coronary artery disease.

\section{Materials and methods:-}

This is a retrospective study performed in the period from January, 2011 until January, 2015. Females included in the study were those who had Computed Tomography Coronary Angiography (CTCA) done within one year of mammography, which showed breast arterial calcification (BAC). Approval for this study was obtained from the Research Ethics Committee.

Patients with previous cardiac surgery or coronary artery stenting were excluded from the study.

All CTCA studies were performed using a single multi-detector 64-slice CT scanner (Optima CT 660, GE Healthcare, South Carolina, USA). Coronary arterial calcification (CAC) score and the severity of coronary artery stenosis, if present, were determined for each patient. Regarding CAC score, all regions with a density over 130 Hounsfield units were considered significant (14).

With respect to coronary artery stenosis, patients were classified into three groups: normal (no stenosis), nonsignificant stenosis (less than 50\% of luminal narrowing), or significant stenosis (equal to or more than 50\% of luminal narrowing) (15).

All mammograms were revised by a single breast-imaging radiologist; with 15 years' experience in breast imaging, who was blinded to the results of CTCA.

Breast arterial calcification (BAC) wasdefined as the presence of parallel linear calcified deposits along the course of a vessel that was seen on mammography,either unilateral or bilateral. BAC was classified into three categories, according to its' severity: Mild BAC (arteries with little calcification with distances greater than $10 \mathrm{~mm}$ between calcified areas), moderate BAC (arteries clearly outlined by calcifications over a considerable proportion of their course), or severe BAC (arteries extensively affected, seen to have almost continuous columns of calcification) (16).

Statistical analysis was performed using SPSS 20.0. Univariate analysis was used to calculate odds ratios for relationships between BACsite and severity, CAC scores and incidence and severity of coronary artery stenosis. $P$ values less than 0.05 were considered statistically significant.

\section{Results:-}

In the study period, 1,495 females were referred to our department for mammography. Forty-four of those females (2.9\%) had breast arterial calcification (BAC), and Computed Tomography Coronary Angiography (CTCA) done within one year of mammography. The mean age of those females was $63.41 \pm 8.12$ years.

Breast arterial calcification was unilateral in 6 females (13.6\%) and bilateral in 38 females (86.4\%), Table 1. The grades of BAC were either moderate or severe. Moderate BAC was present in 22 females (50\%), while severe BAC was present in 22 females (50\%), Table 2. 
Table 1:- Number of cases with Breast Arterial Calcification (BAC) as per site:

\begin{tabular}{|l|l|}
\hline Site of Breast Arterial Calcification (BAC) & Number of Cases \\
\hline Unilateral & 6 \\
\hline Bilateral & 38 \\
\hline
\end{tabular}

Table 2:- Number of cases with Breast Arterial Calcification (BAC) according to severity:

\begin{tabular}{|l|l|}
\hline Severity of Breast Arterial Calcification (BAC) & Number of Cases \\
\hline Moderate & 22 \\
\hline Severe & 22 \\
\hline
\end{tabular}

Coronary arterial calcification (CAC) score was 1 to130 Hounsfield units in 12 cases (27\%), between 130 and 400 Hounsfield units in 14 cases (32\%) and there was no coronary calcification (Zero score) in 18 cases (41\%), table 3. Non-significant coronary artery stenosis was detected in 8 cases $(18.2 \%)$, while the rest of the cases showed no stenosis on CTCA; (81.8\%), Table 4.

Table 3:- Coronary Artery Calcification (CAC) Scores of the study cases:

\begin{tabular}{|l|l|}
\hline Coronary Artery Calcification (CAC) score & Number of Cases \\
\hline No CAC (Zero score) & 18 \\
\hline $1-130$ Hounsfield Units & 12 \\
\hline $130-400$ Hounsfield Units & 14 \\
\hline
\end{tabular}

Table 4:- Incidence of Coronary Artery Stenosis:

\begin{tabular}{|l|l|}
\hline Coronary Artery Stenosis & Number of Cases \\
\hline No stenosis & 36 \\
\hline Non-significant Stenosis & 8 \\
\hline
\end{tabular}

$33.3 \%$ of females with unilateral BAC had no coronary artery calcification on CTCA, while the rest (66.7\%) had 130-400 Hounsfield units CAC score. $25 \%$ had no coronary artery stenosis, while $75 \%$ had non-significant stenosis.

$42.1 \%$ of females with bilateral BAC had no coronary artery calcification on CTCA, $31.6 \%$ had less than 130 Hounsfield units CAC score, while $26.3 \%$ had $130-400$ Hounsfield units CAC score. $77 \%$ of those females had no coronary artery stenosis, while $37.5 \%$ had non-significant stenosis, Table 5.

Table 5:- Correlation of the site of Breast Arterial Calcification (BAC) and Coronary Artery Calcification (CAC) score and Incidence of Coronary Artery Stenosis:

\begin{tabular}{|l|l|l|l|l|l|l|}
\hline $\begin{array}{l}\text { Site of Breast } \\
\text { Arterial } \\
\begin{array}{l}\text { Calcification } \\
\text { (BAC) }\end{array}\end{array}$ & $\begin{array}{l}\text { Total } \\
\text { Number of } \\
\text { Cases }\end{array}$ & $\begin{array}{l}\text { No Coronary } \\
\text { Artery } \\
\text { Calcification } \\
\text { Zero CAC } \\
\text { score) }\end{array}$ & $\begin{array}{l}\text { CAC score 1- } \\
\text { 130 Hounsfield } \\
\text { Units }\end{array}$ & $\begin{array}{l}\text { CAC score } \\
130-400 \\
\text { Hounsfield } \\
\text { Units }\end{array}$ & $\begin{array}{l}\text { No } \\
\text { Coronary } \\
\text { Artery } \\
\text { Stenosis }\end{array}$ & $\begin{array}{l}\text { Non- } \\
\text { significant } \\
\text { Coronary } \\
\text { Artery } \\
\text { stenosis }\end{array}$ \\
\hline Unilateral & 6 & 2 & 0 & 4 & 1 & 3 \\
\hline Bilateral & 38 & 16 & 12 & 10 & 17 & 5 \\
\hline
\end{tabular}

$60 \%$ of females with moderate BAC had no coronary artery calcification on CTCA, 9\% had less than 130 Hounsfield units CAC score, while $27 \%$ had 130-400 Hounsfield units CAC score. 62.5\% of those females had no coronary artery stenosis, while $30 \%$ had non-significant stenosis.

$25 \%$ of females with severe BAC had no coronary artery calcification on CTCA, $41.7 \%$ had less than 130 Hounsfield units CAC score, while $33.3 \%$ had 130-400 Hounsfield units CAC score. $75 \%$ of those females had no coronary artery stenosis, while $25 \%$ had non-significant stenosis, Table 6. 
Table 6:- Correlation of the severity of Breast Arterial Calcification (BAC) and Coronary Artery Calcification (CAC) score and Incidence of Coronary Artery Stenosis:

\begin{tabular}{|c|c|c|c|c|c|c|}
\hline $\begin{array}{l}\text { Severity of } \\
\text { Breast Arterial } \\
\text { Calcification } \\
(\mathrm{BAC})\end{array}$ & $\begin{array}{l}\text { Total } \\
\text { Number of } \\
\text { cases }\end{array}$ & $\begin{array}{l}\text { No Coronary } \\
\text { Artery } \\
\text { Calcification } \\
\text { (Zero CAC } \\
\text { score) }\end{array}$ & $\begin{array}{l}\text { CAC score 1- } \\
130 \text { Hounsfield } \\
\text { Units }\end{array}$ & $\begin{array}{l}\text { CAC score } \\
130-400 \\
\text { Hounsfield } \\
\text { Units }\end{array}$ & $\begin{array}{l}\text { No } \\
\text { Coronary } \\
\text { Artery } \\
\text { Stenosis }\end{array}$ & $\begin{array}{l}\text { Non- } \\
\text { significant } \\
\text { Coronary } \\
\text { Artery } \\
\text { stenosis }\end{array}$ \\
\hline Moderate & 22 & 14 & 2 & 6 & 5 & 3 \\
\hline Severe & 22 & 6 & 9 & 7 & 12 & 4 \\
\hline
\end{tabular}

$15 \%$ of the females with BAC and coronary artery calcification had unilateral BAC, while $85 \%$ of them had bilateral $\mathrm{BAC}$, the correlation of which was statistically significant. There was also a significant difference between females with BAC and coronary artery calcification (59\%) and those with BAC and no coronary artery calcification (41\%). On the other hand, females with severe BAC and non-significant coronary artery stenosis were less than those with moderate $\mathrm{BAC}$ and coronary artery stenosis ( $25 \%$ and $37.5 \%$, respectively). In addition, there was no significant correlation between the severity of BAC and CAC scores $(r: 0.08, P:<0.05)$.

\section{Discussion:-}

Screening mammography is recognized as the most important tool for the detection of breast cancer $(17,18)$.It has been suggested that breast arterial calcification (BAC) seen on mammography could be an indicator of generalized vascular disease $(19,20)$.

In this study, the incidence of coronary artery calcification was more among females with bilateral BAC than those with unilateral BAC, the correlation of which was statistically significant. There was also a significant difference between females with BAC and coronary artery calcification (59\%) and those with BAC and no coronary artery calcification (41\%). Maas et al found that BAC was related to the development of coronary artery calcification; which could be attributed to the fact that a systemic vascular process is expected to occur in the patients with more BAC. However, due different etiologies of BAC and coronary artery calcification, they concluded that mammograms might not be used in CAD risk assessment (14).

On the other hand, there was no significant correlation between the severity of BAC and the CAC scores in this study. Moradiet al also did not find any statistically significant correlation between CAC score and the severity of BAC (21).

In addition, females with severe BAC and non-significant coronary artery stenosis were less than those with moderate BAC and coronary artery stenosis. Zgheib et al found no correlation between BAC and coronary artery disease (CAD), even when CAD severity was considered (13). Penugonda et al also demonstrated that BAC was not positively associated with CAD or acute cardiovascular event (12).

On the contrary, Pecchi et al found a significant association between BAC severity and coronary artery calcification (22). Also, Oliveiraet al stated that the presence of vascular calcifications seen via mammography was an independent risk factor for coronary artery disease (23).

In my opinion, the discrepancy in results between different studies is that there are many variables in these studies that affect the development of CAD; like the difference in age groups and the presence of other systemic disease e.g. hypertension. Further investigation is still recommended to achieve accurate results.

In conclusion, the presence of $\mathrm{BAC}$ is associated with a high incidence of coronary artery calcification. However, the severity of BAC has no significant correlation with CAC scores or CAD on CTCA. 


\section{References:-}

1. Mosca L, Banka CL, Benjamin EJ, Berra K, Bushnell C, Dolor RJ, et al. Evidence-Based Guidelines for Cardiovascular Disease Prevention in Women: 2007 Update. Circulation. 2007; 115:1481-501.

2. Favarato MLCS, Favarato D, Hueb WA, Aldrighi JM. Quality of life in patients with coronary artery disease: comparison between genders. Rev Assoc Med Bras. 2006;52: 236-41.

3. Kataoka M, Warren R, Luben R, Camus J, Denton E, Sala E, et al. How predictive is breast arterial calcification of cardiovascular disease and risk factors when found at screening mammography? AJR Am J Roentgenol. 2006; 187:73-80.

4. Schoepf UJ, Becker CR, Ohnesorge BM, Yucel EK. CT of coronary artery disease. Radiology. 2004; 232:1837.

5. Anderson JW. Whole grains protect against atherosclerotic cardiovascular disease. Proc Nutr Soc. 2003; 62:135-42.

6. Stary HC. Natural history of calcium deposits in atherosclerosis progression and regression. Z Kardiol. 2000; 89(Suppl 2):28-35.

7. Buyukterzi M, Turkvatan A, Buyukterzi Z. Frequency and extent of coronary atherosclerotic plaques in patients with a coronary artery calcium score of zero: An assessment using CT angiography. Diagn Interv Radiol. 2012; 9:111-8.

8. Reddy J, Son H, Smith SJ, Paultre F, Mosca L. Prevalence of breast arterial calcification in an ethnically diverse population of women. Ann Epidemiol. 2005; 15:344-50.

9. Iribarren C, Go AS, Tolstykh I, Sidney S, Johnston SC, Spring DB. Breast vascular calcification and risk of coronary heart disease, stroke, and heart failure. J Womens Health (Larchmt) 2004; 13:381-9.

10. Cetin M, Cetin R, Tamer N. Prevalence of breast arterial calcification in hypertensive patients. Clin Radiol. 2004; 59:92-5.

11. Maas AH, van der Schouw YT, Beijerinck D, Deurenberg JJ, Mali WP, van der Graaf Y. Arterial calcifications seen on mammograms: Cardiovascular risk factors, pregnancy, and lactation. Radiology 2006; 240:33-8.

12. Penugonda N, Billecke SS, Yerkey MW, Rebner M, Marcovitz PA. Usefulness of breast arterial calcium detected on mammography for predicting coronary artery disease or cardiovascular events in women with angina pectoris and/or positive stress tests. Am J Cardiol. 2010; 105:359-61.

13. Zgheib MH, Buchbinder SS, Abi Rafeh N, Elya M, Raia C, Ahern K, et al. Breast arterial calcifications on mammograms do not predict coronary heart disease at coronary angiography. Radiology 2010; 254:367-73.

14. Maas AH, van der Schouw YT, Atsma F, Beijerinck D, Deurenberg JJ, Mali WP, et al. Breast arterial calcifications are correlated with subsequent development of coronary artery calcifications, but their etiology is predominantly different. Eur J Radiol. 2007; 63:396-400.

15. Abdulla J, Asferg C, Kofoed KF. Prognostic value of absence or presence of coronary artery disease determined by 64-slice computed tomography coronary angiography a systematic review and meta-analysis. Int $\mathrm{J}$ Cardiovasc Imaging. 2011; 27:413-20.

16. Fiuza Ferreira EM, Szejnfeld J, Faintuch S. Correlation between intramammary arterial calcifications and CAD. Acad Radiol. 2007; 14:144-50.

17. Weedon-Fekjær H, Romundstad PR, Vatten LJ.Modern mammography screening and breast cancer mortality: Population study.BMJ 2014; 348:g3701.

18. Vainio H, Bianchini F. IARC handbooks of cancer prevention. Vol 7, Breast CancerScreening. Lyon, France: International Agency for Research on Cancer 2002; 128.

19. Markopoulos C, Mantas D, Revenas K, Kouskos E, Tzonou A, Liapis C, et al. Breast arterial calcifications as an indicator of systemic vascular disease. Acta Radiol. 2004; 45:726-9.

20. Taskin F, Akdilli A, Karaman C, Unsal A, Koseoglu K, Ergin F. Mammographically detected breast arterial calcifications: Indicators for arteriosclerotic diseases? Eur J Radiol. 2006; 60:250-5.

21. Moradi M, Adibi A, Abedi M. Relationship between breast arterial calcification on mammography with CT Calcium scoring and coronary CT angiography results. Adv Biomed Res. 2014; 28 (3):79.

22. Pecchi A, Rossi R, Coppi F, Ligabue G, Modena MG, Romagnoli R. Association of breast arterial calcifications detected by mammography and coronary artery calcifications quantified by multislice $\mathrm{CT}$ in a population of post-menopausal women. Radiol Med. 2003; 106:305-12.

23. Oliveira ELC, Freitas-Junior R, Afiune-Neto A, Murta EFC, Ferro JE, Melo AFB. Vascular Calcifications Seen on Mammography: An Independent Factor Indicating Coronary Artery Disease.Clinics (Sao Paulo) 2009; 64(8): 763-767. 